\title{
Optical nonlinearity in low-temperature-grown GaAs: Microscopic limitations and optimization strategies
}

M. Haiml, U. Siegner, F. Morier-Genoud, U. Keller, M. Luysberg, R. C. Lutz, P. Specht, and E. R. Weber

Citation: Appl. Phys. Lett. 74, 3134 (1999); doi: 10.1063/1.124086

View online: https://doi.org/10.1063/1.124086

View Table of Contents: http://aip.scitation.org/toc/apl/74/21

Published by the American Institute of Physics

\section{Articles you may be interested in}

Ultra-short pulse generation by a topological insulator based saturable absorber

Applied Physics Letters 101, 211106 (2012); 10.1063/1.4767919

Large energy soliton erbium-doped fiber laser with a graphene-polymer composite mode locker Applied Physics Letters 95, 141103 (2009); 10.1063/1.3244206

\section{SELF MODE-LOCKING OF LASERS WITH SATURABLE ABSORBERS}

Applied Physics Letters 8, 174 (1966); 10.1063/1.1754541

Structural properties of As-rich GaAs grown by molecular beam epitaxy at low temperatures

Applied Physics Letters 54, 1881 (1989); 10.1063/1.101229

Ultrafast excitonic saturable absorption in ion-implanted InGaAs/InAIAs multiple quantum wells Applied Physics Letters 72, 759 (1998); 10.1063/1.120885

Graphene mode locked, wavelength-tunable, dissipative soliton fiber laser Applied Physics Letters 96, 111112 (2010); 10.1063/1.3367743

\section{HIDEN \\ Instruments for Advanced Science}

Contact Hiden Analytical for further details: W www.HidenAnalytical.com E info@hiden.co.uk CLICK TO VIEW our product catalogue

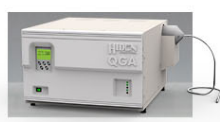

Gas Analysis dynamic measurement of reaction gas streams cataysis and thermal analysis - molecular beam studes fermentation, enviromental and ecological studies

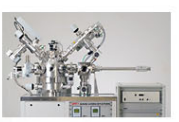

Surface Science UHVTPD SIMS end point detection in in beam etch elemental imaging-surface mapping

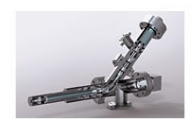

Plasma Diagnostics plasma source characterization etch and depositon process reaction

kinetic studies
analysis of neutral and radical species

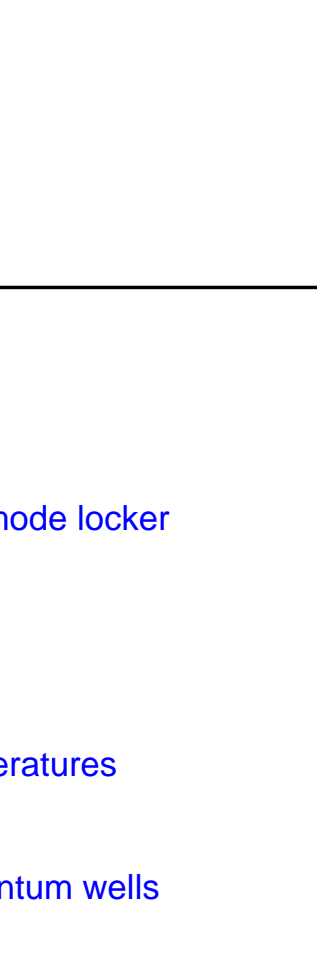




\title{
Optical nonlinearity in low-temperature-grown GaAs: Microscopic limitations and optimization strategies
}

\author{
M. Haiml, ${ }^{\text {a) }}$ U. Siegner, F. Morier-Genoud, and U. Keller \\ Institute of Quantum Electronics, Swiss Federal Institute of Technology, ETH Hönggerberg-HPT, \\ CH-8093 Zürich, Switzerland \\ M. Luysberg \\ Institute of Solid State Research, Research Center Jülich, D-52425 Jülich, Germany \\ R. C. Lutz, P. Specht, and E. R. Weber \\ Department of Materials Science and Mineral Engineering, University of California, Berkeley, \\ California $94720-1760$
}

(Received 11 March 1999; accepted for publication 29 March 1999)

\begin{abstract}
We have quantitatively measured the linear and the nonsaturable absorption as well as the absorption modulation and its recovery time in as-grown and annealed low-temperature (LT) GaAs. Correlation of the optical data with As antisite $\left(\mathrm{As}_{\mathrm{Ga}}\right)$ defect densities yields the absorption cross section and the saturation parameter of the dominant $\mathrm{As}_{\mathrm{Ga}}$ to the conduction-band defect transition. We show that this defect transition is mainly responsible for the large nonsaturable absorption in as-grown LT GaAs with fast recovery times. Reducing the $\mathrm{As}_{\mathrm{Ga}}$ density by annealing yields an optimized material with small nonsaturable absorption, high absorption modulation, and fast recovery times. (C) 1999 American Institute of Physics. [S0003-6951(99)03721-3]
\end{abstract}

Low-temperature (LT) molecular beam epitaxy-grown (MBE) III-V semiconductors have found many applications in ultrafast all-optical gating, ${ }^{1}$ femto- and picosecond laser pulse generation, ${ }^{2}$ and high-bit-rate communications systems. ${ }^{3}$ The advantage of LT materials in these technologies is the ultrafast recovery time of their optical nonlinearity after resonant interband excitation. ${ }^{4}$ The ultrafast recovery time results from trapping of optically excited carriers into defect states introduced by the LT growth. ${ }^{5}$ Carrier trapping into defects has been intensively investigated in recent years, in particular for LT GaAs, which can serve as a model system. ${ }^{4,6-8}$ However, the introduction of defect states may also give rise to new absorption channels, which can affect the strength of the nonlinear optical response. Besides the recovery time, the strength of the nonlinearity is the most important parameter of a material for all-optical switches and saturable absorbers. In fact, we have recently shown that as-grown LT GaAs with fast recovery times suffers from a weak nonlinear optical response in experiments in which the absorptive nonlinearity is exploited. ${ }^{9}$ This study has provided qualitative evidence that the optical transition from the intrinsic As antisite defect $\left(\mathrm{As}_{\mathrm{Ga}}\right)$ to the conduction band (CB) is related to the weak nonlinear optical response in as-grown LT GaAs. ${ }^{9}$

In this letter, we present a quantitative study of the linear and nonlinear optical properties of the transition from $\mathrm{As}_{\mathrm{Ga}}$ defects to the CB for above-band-gap excitation. This study has been made possible by the correlation of the optical data with measurements of the defect density. The linear absorption cross section and the saturation parameter of the $\mathrm{As}_{\mathrm{Ga}}-\mathrm{CB}$ transition have been determined. We show that with reasonable pulse fluences the $\mathrm{As}_{\mathrm{Ga}}-\mathrm{CB}$ transition is difficult to saturate and contributes a major fraction to the nonsaturable absorption losses in as-grown LT GaAs. Most sig-

${ }^{\text {a)} E l e c t r o n i c ~ m a i l: ~ h a i m l @ i q e . p h y s . e t h z . c h ~}$ nificantly, our data demonstrate that the reduction of the $\mathrm{As}_{\mathrm{Ga}}$ density by annealing yields an optimized material which combines fast recovery times with a strong nonlinear optical response. In contrast to earlier work, ${ }^{8}$ we present a comprehensive set of quantitative data which allows for the engineering of the ultrafast nonlinear optical response of LT GaAs in arbitrary switching and absorber devices.

We have studied 500-nm-thick LT-GaAs layers, which were grown by $\mathrm{MBE}$ at an $\mathrm{As}_{4} / \mathrm{Ga}$-flux ratio of 4.5 and various growth temperatures $\left(T_{g}=220-580^{\circ} \mathrm{C}\right)$. The layers are either as grown or have been postgrowth annealed at $600{ }^{\circ} \mathrm{C}$ under arsenic overpressure for $75 \mathrm{~min}$. All layers have been grown on $\mathrm{Al}_{0.15} \mathrm{Ga}_{0.85} \mathrm{As} / \mathrm{AlAs}$ Bragg mirrors and $n^{+}$-GaAs substrates. We have verified that the structural properties of LT-GaAs layers from our MBE system are independent of the substrate type. ${ }^{9} \mathrm{X}$-ray diffraction measurements have shown that all LT-GaAs layers are of good crystalline quality. The concentration of neutral arsenic antisites $\left[\mathrm{As}_{\mathrm{Ga}}^{0}\right]$ was measured by near-infrared absorption (NIRA) (Ref. 10) in the epilayers grown on $n^{+}$substrates. The Bragg mirror samples have been antireflection (AR) coated on the front surface. These samples have been used for the optical studies in a reflection geometry.

Due to the high quality of the AR coating and the Bragg mirrors, the reflectivity $R$ of the whole structure can be approximated by $R=\exp (-2 \alpha d)$, where $\alpha$ is the absorption coefficient, $d$ the physical thickness of the LT-GaAs layer, and $2 d$ the effective thickness in the reflection geometry. The equation assumes ideal Bragg mirrors and AR coatings and neglects standing-wave effects as well as nonlinear refractive-index changes $\Delta n$. We have performed extensive numerical simulations, considering the actual AR coating and Bragg mirror designs, standing-wave effects, and the largest reasonable $\Delta n=0.2 .^{11,12}$ These simulations show that the use of the simple relation $R=\exp (-2 \alpha d)$ only causes a negligible error in $\alpha$. 


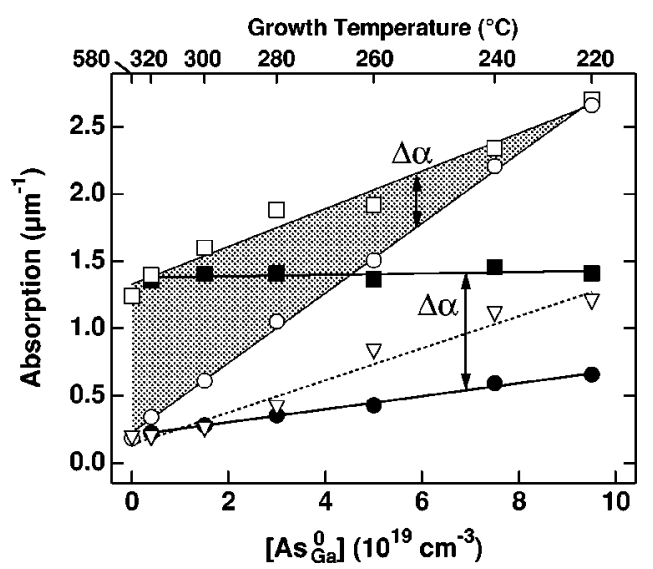

FIG. 1. Linear absorption $\alpha_{\text {lin }}(\square, \boldsymbol{\square})$, nonsaturable absorption $\alpha_{\mathrm{ns}}(\bigcirc, \bullet)$, and additional absorption $\gamma_{\mathrm{ns}}(\nabla)$ for as-grown LT-GaAs samples (open symbols) and their annealed counterparts (filled symbols) vs the neutral As antisite concentration in the as-grown LT-GaAs samples. The upper horizontal axis shows the growth temperature. The absorption modulation $\Delta \alpha$ $=\alpha_{\text {lin }}-\alpha_{\mathrm{ns}}$ is indicated by arrows and by the shaded wedge.

The linear absorption and the absorptive nonlinearity of the LT-GaAs layers have been measured at room temperature with $150 \mathrm{fs}$ pulses for excitation above the band gap at $830 \mathrm{~nm}$. We have measured the reflectivity $R$ versus the pulse energy fluence $F$ in a single-beam experiment. ${ }^{9}$ The experimental data are extrapolated to the linear regime and to high fluences using the traveling wave rate equation model for a two-level absorber. ${ }^{13,14}$ With respect to the concept of this model, we recall that the reflectivity of an ideal lossless absorber saturates at $R_{\mathrm{ns}}=1$ at high fluences. $R_{\mathrm{ns}}=1$ corresponds to an absorption $\alpha_{\mathrm{ns}}=0$. The model assumes that the reflectivity of a real absorber saturates at $R_{\mathrm{ns}}<1$, corresponding to $\alpha_{\mathrm{ns}}>0$, and explicitly introduces $R_{\mathrm{ns}}<1$ as an additional parameter. $R_{\mathrm{ns}}\left(\right.$ or $\left.\alpha_{\mathrm{ns}}\right)$ accounts for the differences between a two-level absorber and a real semiconductor. Different processes can contribute to $\alpha_{\text {ns }}$ : (i) absorption, which only decreases at fluences much higher than the fluences which fully saturate the two-level absorber; and (ii) induced absorption, which only occurs in the nonlinear regime, e.g., absorption out of excited states. Very good fits to the experimental data are obtained with this model, see Ref. 9, for an example. From the fits, one determines the linear and nonsaturable reflectivities $R_{\operatorname{lin}}=\exp \left(-2 \alpha_{\operatorname{lin}} d\right)$ and $R_{\mathrm{ns}}$ $=\exp \left(-2 \alpha_{\mathrm{ns}} d\right)$ (or the linear and nonsaturable absorption $\alpha_{\operatorname{lin}}$ and $\left.\alpha_{\mathrm{ns}}\right)$, and the saturation fluence of the two-level absorber. The saturation fluence is a measure of the pulse fluence at which significant changes of the absorption occur. The absorption modulation is given by $\Delta \alpha=\alpha_{\text {lin }}-\alpha_{\mathrm{ns}}$. For the modulation of the reflectivity one obtains $\Delta R=R_{\mathrm{ns}}$ $-R_{\operatorname{lin}}=\exp \left(-2 \alpha_{\text {ns }} d\right)[1-\exp (-2 \Delta \alpha d)]$ and for the nonsaturable losses in reflectivity $\Delta R_{\mathrm{ns}}=1-R_{\mathrm{ns}}=1-\exp$ $\left(-2 \alpha_{\text {ns }} d\right)$. With respect to applications, we note that an increase of $\alpha_{\mathrm{ns}}$ increases $\Delta R_{\mathrm{ns}}$ and decreases $\Delta R$ of a saturable absorber device. Moreover, $\Delta R$ decreases with decreasing $\Delta \alpha$.

Figure 1 shows $\alpha_{\text {lin }}$ and $\alpha_{\text {ns }}$ for the as-grown LT-GaAs samples and their annealed counterparts versus the $\mathrm{As}_{\mathrm{Ga}}^{0}$ density in the as-grown samples. It is found that the linear above-band-gap absorption strongly increases with increasing defect density in as-grown LT GaAs, in agreement with Refs. 15 and 16. We recall that the $\mathrm{As}_{\mathrm{Ga}}$ is the intrinsic point defect in LT GaAs whose density increases to about $10^{20} \mathrm{~cm}^{-3}$ with decreasing growth temperature. ${ }^{10}$ In asgrown layers, more than $90 \%$ of the $\mathrm{As}_{\mathrm{Ga}}$ are neutral while the rest is ionized. ${ }^{10}$ For below-band-gap energies, the $\mathrm{As}_{\mathrm{Ga}}^{0}-\mathrm{CB}$ transition has a much higher absorption cross section than the transition from the valence band to the ionized $\mathrm{As}_{\mathrm{Ga}}^{+}$(Ref. 17) and the second optical ionization of $\mathrm{As}_{\mathrm{Ga}}^{+}{ }^{18}$ Consequently, we attribute the excess linear absorption in as-grown $\mathrm{GaAs}$ to the $\mathrm{As}_{\mathrm{Ga}}^{0}-\mathrm{CB}$ transition. We refer to the $\mathrm{As}_{\mathrm{Ga}}^{0}-\mathrm{CB}$ absorption as to $\alpha_{T}$, given by $\alpha_{T}$ $=\alpha_{\operatorname{lin}}-\alpha_{\operatorname{lin}}(\mathrm{HT})\left[\alpha_{\operatorname{lin}}(\mathrm{HT})\right.$ linear absorption in standard, high-temperature GaAs]. Our quantitative data allow for the determination of the absorption cross-section $\sigma$ of this transition at $830 \mathrm{~nm}$. One obtains $\sigma=1.4 \times 10^{-16} \mathrm{~cm}^{2}$ from $\alpha_{T}$ $=\sigma\left[\mathrm{As}_{\mathrm{Ga}}^{0}\right]$ and the linear fit to the data in Fig. 1. This value is a reasonable extrapolation of the results for sub-band-gap photon energies. ${ }^{17}$

From $\sigma$, the saturation fluence $F_{\text {sat }}=\hbar \omega / \sigma$ ( $\hbar \omega$ photon energy) (Ref. 14) of the $\mathrm{As}_{\mathrm{Ga}}^{0}-\mathrm{CB}$ transition can be quantitatively determined. One obtains $F_{\text {sat }}=1700 \mu \mathrm{J} / \mathrm{cm}^{2}$, in good agreement with the results for sub-band-gap photon energies. ${ }^{19}$ At this fluence, the absorption of the $\mathrm{As}_{\mathrm{Ga}}^{0}-\mathrm{CB}$ transitions significantly decreases. In contrast, the saturation fluence of the interband transition in GaAs is, typically, below $50 \mu \mathrm{J} / \mathrm{cm}^{2}$. The comparison shows that $\alpha_{T}$ is hardly decreased by fluences which almost fully saturate the interband transition. Therefore, the $\mathrm{As}_{\mathrm{Ga}}^{0}-\mathrm{CB}$ absorption fully contributes to the nonsaturable absorption $\alpha_{\mathrm{ns}}$.

Surprisingly, further quantitative analysis shows that $\alpha_{\mathrm{ns}}>\alpha_{T}$ in as-grown LT GaAs. Since $\alpha_{T}$ is nonsaturable, one can write $\alpha_{\mathrm{ns}}=\alpha_{T}+\gamma_{\mathrm{ns}}$, where $\gamma_{\mathrm{ns}}$ is additional nonsaturable absorption. Figure 1 shows that $\gamma_{\mathrm{ns}}$ makes up about $40 \%$ of the total nonsaturable absorption $\alpha_{\mathrm{ns}}$ in as-grown LT GaAs. Thus, the nonsaturable $\mathrm{As}_{\mathrm{Ga}}^{0}-\mathrm{CB}$ absorption $\alpha_{T}$ contributes the major fraction to $\alpha_{\mathrm{ns}}$. However, $\alpha_{T}$ cannot account for a reduction of the absorption modulation $\Delta \alpha$ $=\alpha_{\text {lin }}-\alpha_{\text {ns }}$ since $\alpha_{T}$ contributes equal amounts to both $\alpha_{\operatorname{lin}}$ and $\alpha_{\mathrm{ns}}$. From the above relations, one finds $\Delta \alpha$ $=\alpha_{\operatorname{lin}}(\mathrm{HT})-\gamma_{\mathrm{ns}}$. Figure 1 shows that in as-grown LT GaAs $\Delta \alpha$ decreases and $\gamma_{\mathrm{ns}}$ increases with the $\mathrm{As}_{\mathrm{Ga}}^{0}$ density. In devices based on as-grown LT GaAs, the large nonsaturable $\mathrm{As}_{\mathrm{Ga}}^{0}-\mathrm{CB}$ absorption increases the nonsaturable losses in reflectivity $\Delta R_{\mathrm{ns}}$ and limits the reflectivity modulation $\Delta R$. Moreover, $\Delta R$ can be strongly reduced by $\gamma_{\mathrm{ns}}$, which contributes to the nonsaturable absorption and reduces the absorption modulation.

With respect to the microscopic origin of $\gamma_{\mathrm{ns}}$, we note that $\gamma_{\mathrm{ns}}$ seems to be intimately related to the LT growth since it increases linearly with the $\mathrm{As}_{\mathrm{Ga}}^{0}$ density in as-grown LT GaAs (see Fig. 1). The mechanism responsible for the additional absorption $\gamma_{\mathrm{ns}}$ is not yet fully understood. A possible reason for $\gamma_{\mathrm{ns}}$ is free-carrier absorption (FCA) due to carriers high in the $\mathrm{CB}$. These carriers can be generated by the $\mathrm{As}_{\mathrm{Ga}}^{0}-\mathrm{CB}$ transition in as-grown LT GaAs. The FCA hypothesis is in line with the linear dependence of $\gamma_{\mathrm{ns}}$ on the $\mathrm{As}_{\mathrm{Ga}}^{0}$ density.

Annealing leads to a reduction of the $\mathrm{As}_{\mathrm{Ga}}^{0}$ and $\mathrm{As}_{\mathrm{Ga}}^{+}$ densities ${ }^{10}$ and to the formation of As precipitates. ${ }^{20}$ Figure 1 shows that the linear absorption increases only very slightly with the excess As content in annealed LT, in agreement 


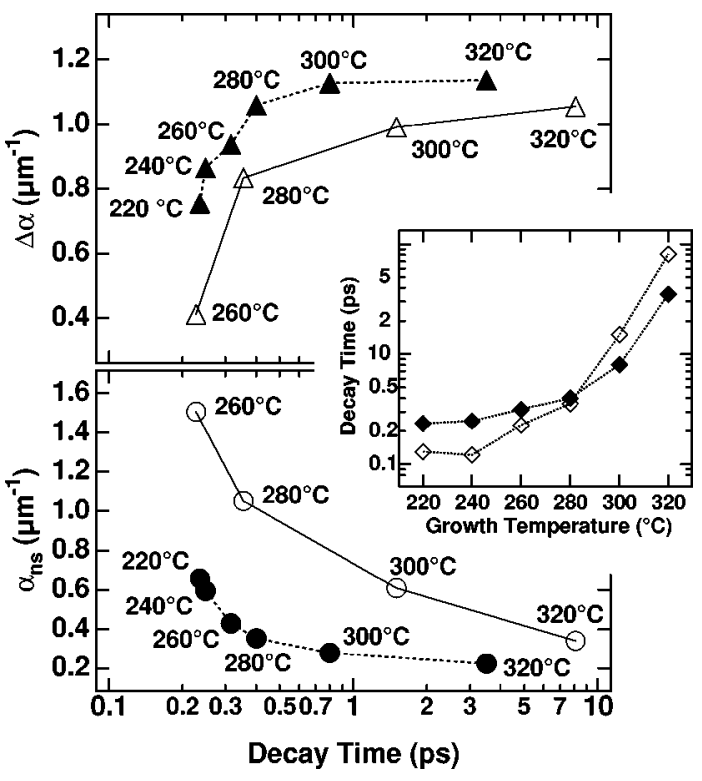

FIG. 2. Absorption modulation $\Delta \alpha(\triangle, \mathbf{\Lambda})$ and nonsaturable absorption $\alpha_{\text {ns }}$ $(\bigcirc, \bullet)$ vs decay times for as-grown (open symbols) and annealed (filled symbols) LT GaAs. Labels: growth temperatures. Inset: 1/e decay times of as-grown $(\diamond)$ and annealed $(\diamond)$ LT GaAs vs growth temperature. The decay times have been determined at a carrier density of about $5 \times 10^{18} \mathrm{~cm}^{-3}$.

with the surface plasmon model for precipitates. $^{21}$ The absorption $\alpha_{T}$ is almost totally removed by annealing, which greatly improves the nonsaturable absorption $\alpha_{\text {ns }}$. Since $\alpha_{T}$ $\approx 0$ in annealed LT GaAs, the remaining nonsaturable absorption $\alpha_{\mathrm{ns}}$ is due to $\gamma_{\mathrm{ns}}$. Figure 1 shows that $\alpha_{\mathrm{ns}} \approx \gamma_{\mathrm{ns}}$ in annealed LT GaAs is substantially smaller than $\gamma_{\mathrm{ns}}$ in asgrown LT GaAs. The relation $\Delta \alpha=\alpha_{\text {lin }}(\mathrm{HT})-\gamma_{\mathrm{ns}}$ implies that the absorption modulation $\Delta \alpha$ is also increased by annealing, as observed in Fig. 1. In devices, the reduction of $\alpha_{T}$ and $\alpha_{\text {ns }}$ and the increase of $\Delta \alpha$ upon annealing improve both the nonsaturable losses in reflectivity and the reflectivity modulation. We note that photoexcitation of electrons out of precipitates in annealed LT GaAs (Ref. 22) can generate electrons high in the $\mathrm{CB}$ so that the FCA hypothesis could also explain the small nonsaturable absorption $\alpha_{\mathrm{ns}} \approx \gamma_{\mathrm{ns}}$ in annealed LT GaAs.

In order to fully evaluate the potential of LT GaAs for applications in ultrafast nonlinear optics, the recovery time of the absorption modulation was measured in pump-probe experiments with $150 \mathrm{fs}$ pulses at $830 \mathrm{~nm}$. The 1/e decay times versus growth temperature in the inset of Fig. 2 show that annealing results only in a slight increase of the recovery time for $T_{g} \leqslant 280^{\circ} \mathrm{C}$ and even yields a faster response at higher growth temperatures. Since annealing reduces the density of $\mathrm{As}_{\mathrm{Ga}}^{+}$, which are electron traps, ${ }^{7,23}$ we conclude that the As precipitates maintain fast recovery times.

Figure 2 correlates the absorption modulation and the nonsaturable absorption with the recovery time. As-grown LT GaAs with a fast recovery time has only limited absorption modulation and high nonsaturable absorption. The reason for this poor performance is that very large densities of neutral $\mathrm{As}_{\mathrm{Ga}}^{0}$ are incorporated when the material is grown at very low temperatures to obtain large densities of ionized $\mathrm{As}_{\mathrm{Ga}}^{+}$electron traps and a fast recovery time. Annealed LT $\mathrm{GaAs}$ is clearly superior to as-grown material since it com- bines high modulation and small nonsaturable absorption losses with a fast, sub-ps, recovery time. The material optimization by annealing is based on the reduction of the $\mathrm{As}_{\mathrm{Ga}}^{0}$ density in order to reduce the nonsaturable absorption from the $\mathrm{As}_{\mathrm{Ga}}^{0}-\mathrm{CB}$ transition, and on the decrease of $\gamma_{\mathrm{ns}}$. The fast time response is maintained by the As precipitates formed upon annealing. We like to stress that the data of Figs. 1 and 2 allow for the engineering of the ultrafast nonlinear optical response of LT-GaAs-based devices. For a given recovery time, the achievable absorption modulation and the nonsaturable absorption can be determined from Fig. 2. The resulting modulation of the transmission/reflectivity can then be easily calculated for devices of arbitrary thickness. The correlation of the optical data with the $\mathrm{As}_{\mathrm{Ga}}^{0}$ density in Fig. 1 provides the recipe for the MBE growth of the LT-GaAs layer of the device.

This work has been supported by the Swiss National Science Foundation. The materials characterization at UC Berkeley was funded by the Air Force Office of Scientific Research under Grant No. F49620-98-1-0135.

${ }^{1}$ H. S. Loka and P. W. E. Smith, IEEE Photonics Technol. Lett. 10, 1733 (1998).

${ }^{2}$ U. Keller, K. J. Weingarten, F. X. Kärtner, D. Kopf, B. Braun, I. D. Jung, R. Fluck, C. Hönninger, N. Matuschek, and J. Aus der Au, IEEE J. Sel. Top. Quantum Electron. 2, 435 (1996).

${ }^{3}$ R. Takahashi, Y. Kawamura, and H. Iwamura, Appl. Phys. Lett. 68, 153 (1996)

${ }^{4}$ S. Gupta, M. Y. Frankel, J. A. Valdmanis, J. F. Whitaker, G. A. Mourou, F. W. Smith, and A. R. Calawa, Appl. Phys. Lett. 59, 3276 (1991).

${ }^{5}$ G. D. Witt, Mater. Sci. Eng., B 22, 9 (1993).

${ }^{6}$ A. J. Lochtefeld, M. R. Melloch, J. C. P. Chang, and E. S. Harmon, Appl. Phys. Lett. 69, 1465 (1996).

${ }^{7}$ U. Siegner, R. Fluck, G. Zhang, and U. Keller, Appl. Phys. Lett. 69, 2566 (1996).

${ }^{8}$ H. S. Loka, S. D. Benjamin, and P. W. E. Smith, IEEE J. Quantum Electron. 34, 1426 (1998)

${ }^{9}$ M. Haiml, U. Siegner, F. Morier-Genoud, U. Keller, M. Luysberg, P. Specht, and E. R. Weber, Appl. Phys. Lett. 74, 1269 (1999).

${ }^{10}$ X. Liu, A. Prasad, W. M. Chen, A. Kurpiewski, A. Stoschek, Z. LilientalWeber, and E. R. Weber, Appl. Phys. Lett. 65, 3002 (1994).

${ }^{11}$ Y. H. Lee, A. Chavez-Pirson, S. W. Koch, H. M. Gibbs, S. H. Park, J. Morhange, A. Jeffery, N. Peyghambarian, L. Banyai, A. C. Gossard, and W. Wiegmann, Phys. Rev. Lett. 57, 2446 (1986).

${ }^{12}$ J. U. Kang, M. Y. Frankel, J.-W. Huang, and T. F. Kuech, Appl. Phys. Lett. 70, 1560 (1997).

${ }^{13}$ G. P. Agrawal and N. A. Olsson, IEEE J. Quantum Electron. 25, 2297 (1989).

${ }^{14}$ L. R. Brovelli, U. Keller, and T. H. Chiu, J. Opt. Soc. Am. B 12, 311 (1995).

${ }^{15}$ S. U. Dankowski, D. Streb, M. Ruff, P. Kiesel, M. Kneissl, B. Knüpfer, G. H. Döhler, U. D. Keil, C. B. Sørenson, and A. K. Verma, Appl. Phys. Lett. 68, 37 (1996).

${ }^{16}$ K. Khachaturyan, E. R. Weber, and J. Horigan, Phys. Rev. B 46, 1365 (1992).

${ }^{17}$ P. Silverberg, P. Omling, and L. Samuelson, Appl. Phys. Lett. 52, 1689 (1988).

${ }^{18}$ P. Omling, P. Silverberg, and L. Samuelson, Phys. Rev. B 38, 3606 (1988).

${ }^{19}$ A. L. Smirl, G. C. Valley, K. M. Bohnert, and T. F. Boggess, IEEE J. Quantum Electron. 24, 289 (1988).

${ }^{20}$ M. R. Melloch, N. Otsuka, J. M. Woodall, A. C. Warren, and J. L. Freeouf, Appl. Phys. Lett. 57, 1531 (1990).

${ }^{21}$ D. D. Nolte, J. Appl. Phys. 76, 3740 (1994).

${ }^{22}$ D. T. McInturff, J. M. Woodall, A. C. Warren, N. Braslau, G. D. Pettit, P. D. Kirchner, and M. R. Melloch, Appl. Phys. Lett. 60, 448 (1992).

${ }^{23}$ Z. Liliental-Weber, J. Ager, D. Look, X. W. Lin, X. Liu, J. Nishio, K. Nichols, W. Schaff, W. Swider, K. Wang, J. Wasburn, E. R. Weber, and J. Whitaker, in Proceedings of the Eighth Conference on Semi-insulating III-V Materials, edited by M. Godlewski (World Scientific, Singapore, 1994), p. 305. 